\title{
New Developments in Respiratory Support for Preterm Infants
}

\author{
Deepak Jain, MD ${ }^{1} \quad$ Eduardo Bancalari, MD ${ }^{1}$ \\ ${ }^{1}$ Division of Neonatology, Department of Pediatrics, University of \\ Miami Miller School of Medicine, Miami, Florida \\ Am J Perinatol 2019;36(suppl S2):S13-S17.

\begin{abstract}
Address for correspondence Eduardo Bancalari, MD, Division of Neonatology, Department of Pediatrics, University of Miami Miller School of Medicine, Miami, FL 33136

(e-mail: ebancalari@med.miami.edu).
\end{abstract}

\begin{abstract}
\section{Keywords}

- respiratory support

- preterm infant

- endotracheal Intubation

The evolution of neonatal respiratory support has been one of the cornerstones for the advancements in neonatal-perinatal medicine, allowing survival of infants previously considered not viable. There is an increasing focus on developing strategies which are not only lifesaving but also minimize lung and other organ systems injury, thereby reducing long-term morbidities. Respiratory support immediately after birth is an area that had lagged behind in terms of evidence base and technological advancements until recently. Some of these advancements include use of a respiratory function monitors for measuring flow and tidal volume, new evidence for oxygen supplementation and monitoring, and the efforts to formulate an ideal strategy for establishing functional residual capacity after birth. Increasing evidence for the benefits of avoiding invasive ventilation on reduction of bronchopulmonary dysplasia has resulted in efforts to further reduce the need for endotracheal intubation by applying newer strategies such as less invasive surfactant instillation, noninvasive high-frequency oscillatory ventilation, or use of high flow nasal cannula oxygen. For infants requiring mechanical ventilation, newer strategies such as volume targeted ventilation or neurally adjusted ventilation are being evaluated to reduce ventilator induced lung injury. Despite these advances, there are significant challenges, including lack of conclusive evidence base for many of currently used respiratory strategies, no reduction in the incidence of bronchopulmonary dysplasia in the last decade, and difficulties in defining outcome measures that better reflect long-term respiratory health.
\end{abstract}

Increasing survival of premature infants in the last 50 years has been associated with significant challenges in supporting these infants after birth. One of these challenges has been to develop effective respiratory support strategies while avoiding injury to the lungs and other organ systems. During the last few decades, increasing knowledge from animal and clinical research in combination with technological advancements has resulted in significant progress in respiratory support of these infants. Some of the recent advances with current evidence are reviewed below (-Table $\mathbf{1}$ ).

\section{Respiratory Support at Birth}

A large proportion of extremely preterm infants require respiratory support at birth, which is frequently lifesaving but can also produce complications with long-term implications. The initial steps for successful fetal to neonatal transition are clearance of lung fluid and establishment of functional residual capacity. Sustained inflation (SI) during the first few positive pressure breaths after birth was shown in animal studies to achieve these goals quicker than regular intermittent positive pressure ventilation (IPPV). Clinical trials evaluating SI in preterm infants have failed to show similar beneficial effects, with one recent large randomized controlled trial (RCT) stopped early due to increased mortality at less than 48 hours in infants who received SI when compared with regular IPPV., ${ }^{1,2}$

There is increasing evidence that monitoring of ventilation, subjectively by observing chest rise or indirectly by its effect on increase in heart rate, may be inadequate. The use
Copyright (c) 2019 by Thieme Medical Publishers, Inc., 333 Seventh Avenue, New York, NY 10001, USA. Tel: +1(212) 584-4662.
DOI https://doi.org/ 10.1055/s-0039-1691817. ISSN $0735-1631$. 
Table 1 Advances in respiratory support strategies and some recent evidence

\begin{tabular}{|c|c|}
\hline Respiratory support strategy & Recent evidence \\
\hline $\begin{array}{l}\text { In the delivery room: } \\
\text { - Respiratory function } \\
\text { monitoring } \\
\text { - Sustained inflation at birth }\end{array}$ & $\begin{array}{l}\text { - A small feasibility study showed reduction in mask leak and intubation rate with RFM } \\
\text { use. }{ }^{3} \text { No studies evaluating clinical outcomes. } \\
\text { - Meta-analysis of six RCTs showed no significant effect when compared with regular PPV } \\
\text { (RR }=0.85 ; 95 \% \mathrm{Cl}: 0.65-1.12) .{ }^{1} \\
\text { - A multicenter RCT comparing } \mathrm{SI} \text { with IPPV in } 460 \text { extremely preterm infants showed } \\
\text { increased mortality at less than } 48 \mathrm{~h} \text { of age }(7.4 \text { vs. } 1.4 \% \text {, respectively, adjusted risk } \\
\text { difference }=5.6 \% ; 95 \% \mathrm{Cl}: 2.1-9.1 \%) \text {. The rate of death or } \mathrm{BPD} \text { at } 36 \text { weeks PMA did } \\
\text { not differ between the groups. ( } 63.7 \% \text { in } \mathrm{SI} \text { group vs. } 59.2 \% \text { in standard IPPV group). } \\
\text { - Meta-analysis of } 10 \mathrm{RCTs} \text { comparing low (0.21-0.5) vs. high } \mathrm{FiO}_{2}(0.51-1.0) \text { in preterm } \\
\text { infants less than } 35 \text { weeks of gestation showed no effect on mortality or other } \\
\text { morbidities. }\end{array}$ \\
\hline - LISA & $\begin{array}{l}\text { - Meta-analysis of six RCTs comparing LISA with intubation and surfactant use in } 895 \\
\text { preterm infants on CPAP showed reduced incidence of death or BPD (RR =0.75; } 95 \% \\
\text { CI: } 0.59-0.94, p=0.01 \text { ) with use of LISA. }{ }^{7} \text { Not all studies have compared LISA to InSurE } \\
\text { and procedure side effects have not been consistently reported. }\end{array}$ \\
\hline - Noninvasive HFOV & $\begin{array}{l}\text { - Randomized crossover study in } 30 \text { preterm infants showed lower transcutaneous } \mathrm{CO}_{2} \\
\text { values during noninvasive HFOV compared with nCPAP: } 47.5 \pm 7.6 \text { vs. } 49.9 \pm 7.2 \mathrm{~mm} \\
\mathrm{Hg} \text {, respectively }(p=0.0007) .18\end{array}$ \\
\hline $\begin{array}{l}\text { - High flow nasal } \\
\text { cannula (HFNC) }\end{array}$ & $\begin{array}{l}\text { - A meta-analysis of three studies comparing HFNC with CPAP as primary respiratory } \\
\text { support in infants }>28 \text { weeks of } \mathrm{GA} \text {, did not show significant difference in the risk of } \\
\text { treatment failure (risk difference }=0.03 ; 95 \% \mathrm{CI}:-0.03 \text { to } 0.08) .{ }^{10} \\
\text { - A recent multicenter RCT comparing HFNC with CPAP for early RDS was stopped early } \\
\text { due to higher incidence of treatment failure in HFNC group as compared with CPAP: } \\
25.5 \text { vs. } 13.3 \% \text {, respectively, } p<0.001 .9 \\
\text { - A meta-analysis of five studies comparing HFNC with CPAP for postextubation } \\
\text { respiratory support did not show significant difference in the risk of extubation failure: } \\
\text { RR }=1.18 ; 95 \% \mathrm{Cl}: 0.91-1.52, p=0.21 .{ }^{10}\end{array}$ \\
\hline - Volume targeted ventilation & $\begin{array}{l}\text { - Meta-analysis of } 20 \text { randomized trials comparing volume targeted modes with pressure } \\
\text { limited ventilation showed reduction in death or BPD at } 36 \text { weeks of gestation } \\
(\mathrm{RR}=0.73 ; 95 \% \mathrm{Cl}: 0.59-0.89) \text {, and less pneumothorax }(\mathrm{RR}=0.52 ; 95 \% \\
\mathrm{Cl}: 0.31-0.87) \text {, severe } \mathrm{IVH}(\mathrm{RR}=0.53 ; 95 \% \mathrm{Cl}: 0.37-0.77) \text {, and severe IVH or PVL } \\
(\mathrm{RR}=0.47 ; 95 \% \mathrm{Cl}: 0.27-0.80) .^{12}\end{array}$ \\
\hline - HFOV with VG & $\begin{array}{l}\text { - A randomized crossover study in } 20 \text { preterm infants showed improved maintenance of } \\
\text { target VT and reduced incidence of hypocarbia and hypercarbia during HFOV + VG } \\
\text { period as compared with HFOV. }{ }^{13}\end{array}$ \\
\hline - NAVA & $\begin{array}{l}\text { - A recent Cochrane's review found one RCT comparing NAVA with pressure controlled } \\
\text { triggered ventilation showed no effect on clinical outcomes. }\end{array}$ \\
\hline - Oxygen saturation targets & $\begin{array}{l}\text { - A meta-analysis of five RCTs enrolling 4,965 preterm infants showed decreased incidence of } \\
\mathrm{BPD}(\mathrm{RR}=0.81 ; 95 \% \mathrm{Cl}: 0.74-0.90) \text {, and treated } \mathrm{ROP}(\mathrm{RR}=0.74 ; 95 \% \mathrm{Cl}: 0.63-0.86) \text {, but } \\
\text { increased risk of death before discharge }(\mathrm{RR}=1.17 ; 95 \% \mathrm{Cl}: 1.03-1.12) \text {, and severe } \\
\text { necrotizing enterocolitis ( } \mathrm{RR}=1.33 ; 95 \% \mathrm{Cl}: 1.10-1.61) \text { in the lower } \mathrm{SpO}_{2} \text { target }(85-89 \%) \\
\text { in comparison to higher target } \mathrm{SpO}_{2} \text { group }(91-95 \%)\end{array}$ \\
\hline - Automated $\mathrm{FiO}_{2}$ control & $\begin{array}{l}\text { - A meta-analysis of } 10 \text { studies showed that automated } \mathrm{FiO}_{2} \text { control improved time spent } \\
\left.\text { within the target } \mathrm{SpO}_{2} \text { range (mean difference }=12.8 \% ; 95 \% \mathrm{Cl}: 6.5-19.2 \%\right) \text {, periods of } \\
\text { hyperoxia (mean difference }=-8.8 \% ; 95 \% \mathrm{Cl}:-15 \text { to }-2.7 \%) \text {, and severe hypoxia } \\
\left(\mathrm{SpO}_{2}<80 \% \text {; mean difference }=-0.9 \% ; 95 \% \mathrm{Cl}:-1.5 \text { to }-0.4 \%\right) .\end{array}$ \\
\hline
\end{tabular}

Abbreviations: BPD, bronchopulmonary dysplasia; $\mathrm{Cl}$, confidence interval; CPAP, continuous positive airway pressure; IPPV, intermittent positive pressure ventilation; LISA, less invasive surfactant administration; NAVA, neurally adjusted ventilatory assist; RCT, randomized controlled trial; RFM, respiratory function monitor; $\mathrm{RR}$, risk ratio; $\mathrm{SI}$, sustained inflation; $\mathrm{SpO}_{2}$, pulse oximetry monitors; VG, volume guarantee; $\mathrm{VT}$, tidal volume.

of respiratory function monitor to objectively monitor ventilation parameters is one of the strategies with early results showing reduction in mask leaks and lower rates of excessive tidal volume. ${ }^{3}$ The studies evaluating the impact of these monitors on clinical outcomes are currently underway and results should clarify their role in the delivery room.
Another question that has been evaluated in the last decade is oxygen supplementation during resuscitation in the delivery room. Increasing evidence suggests that starting resuscitation with $100 \%$ oxygen is associated with worse outcomes as compared with lower oxygen concentration, especially in term infants. The current Neonatal Resuscitation Program. guidelines recommend using a $\mathrm{FiO}_{2}$ of 0.21 to 
0.3 for initiating resuscitation in very preterm infants but the questions of optimal oxygen concentration and how to titrate it, remains to be answered. ${ }^{4}$

\section{Strategies for Prevention of Endotracheal Intubation}

Endotracheal intubation and mechanical ventilation are the main risk factors for bronchopulmonary dysplasia (BPD) and its avoidance by using noninvasive support has been shown to decrease the incidence of BPD. ${ }^{5}$ The impact of this strategy on long-term respiratory function is not clear. A recent large cohort study evaluating long-term outcomes during three different periods showed worse airway function in children treated during the period when noninvasive respiratory support was used more frequently. ${ }^{6}$ One of the limitations of avoiding endotracheal intubation in premature infants after birth is the inability to use conventional methods of surfactant instillation. This may potentially result in increased oxygen exposure and associated pulmonary injury. To overcome this limitation, innovative methods for surfactant instillation such as using a catheter or feeding tube, via nebulization, or laryngeal mask have been evaluated in the last decade. The most evaluated of these methods has been tracheal instillation of surfactant by a catheter or feeding tube that has been shown to decrease the need for mechanical ventilation and BPD when compared with intubation in preterm infants stabilized on nasal continuous positive airway pressure (CPAP). ${ }^{7}$ Some of the questions that remain to be answered include ideal technique, equipment, or the efficacy in the more immature infants.

A significant limitation of the commonly used methods of noninvasive support is the high failure rates requiring endotracheal intubation and mechanical ventilation, especially in infants at lower gestational ages, who are at higher risk for morbidities and mortality.

Noninvasive high frequency oscillatory ventilation is one of the strategies currently being evaluated to improve gas exchange during noninvasive ventilation. This mode has been evaluated so far in animal and small physiologic studies and has shown some improvement in $\mathrm{CO}_{2}$ removal when compared with CPAP alone. ${ }^{8}$ There is currently limited data on the optimal settings, or clinical efficacy and safety, with no studies evaluating impact on long-term outcomes.

High-flow nasal cannula (HFNC) is another noninvasive respiratory support mode used with increasing frequency in the last few years. The main advantages are patient comfort and ease of use when compared with CPAP or nasal intermittent mandatory ventilation. There is increasing evidence of its inferiority as a primary respiratory support mode in preterm infants greater than 28 weeks of gestational age or as a mode of choice for postextubation respiratory support when compared with CPAP. ${ }^{9,10}$ Another use of HFNC is in convalescing preterm infants requiring long-term noninvasive respiratory support, but there is no clear evidence of long-term benefits.

The increasing use of HFNC in extremely preterm infants has brought a conundrum for researchers and epidemiolo- gists on defining the severity of BPD in these infants. Because these devices generate variable positive pressure and deliver different effective $\mathrm{FiO}_{2}$ at different gas flows and clinical conditions, the accurate categorization of these infants according to the most common definition of BPD severity is challenging. There have been recent attempts to overcome these challenges by proposing different definitions of BPD. ${ }^{11}$

\section{Newer Modes of Mechanical Ventilation}

Mechanical ventilation for neonates has advanced significantly in the last few decades with newer microprocessor controlled ventilators with ever improving capabilities for synchronization of breaths, adjustment for gas leaks, accurate measurement of small tidal volumes, and automation of adjustments of peak pressure, rate, and inspired oxygen. These capabilities have resulted in the development of newer modes of mechanical ventilation, some of which have been shown to improve outcomes.

The ability to provide volume-targeted ventilation for neonates is one of these advances. A recent meta-analysis of studies using different volume targeting strategies showed reduced incidence of death or BPD, pneumothorax, and severe intraventricular hemorrhage when compared with pressure control modes. ${ }^{12}$ One of the volume targeting strategies that has been comparatively better studied is volume guarantee (VG) ventilation in which the ventilator measures exhaled tidal volume (VT) for each breath and adjusts peak inspiratory pressure to deliver a set VT. This mode is gaining acceptance among neonatologists, though there are limited data on the impact on respiratory outcomes, best tidal volume targets for different conditions or an ideal strategy for weaning off the ventilator when using this mode of ventilation. Another use of VG, currently under investigation, is using it in combination with high-frequency oscillatory ventilation so that clinicians can set a target VT and the ventilator adjusts the oscillation amplitude accordingly. There are some initial reports of better maintenance of VT and $\mathrm{PaCO}_{2}$, but there are no data on clinical outcomes or best settings to choose for different clinical conditions. ${ }^{13}$

Synchronization of positive pressure breaths with infant's respiratory effort may reduce the need for respiratory support and, thereby, decreases lung injury. Some of the drawbacks of commonly used synchronization methods utilizing gas flow or negative pressure as a trigger include the effects of gas leak and delay in trigger resulting in ventilator-patient asynchrony. Neurally adjusted ventilatory assist (NAVA) is one of the modes which overcome these problems by detecting the electrical activity of the diaphragm. This ventilator provides proportional assist ventilation increasing airway pressure in proportion to the strength of the electrical signal captured from the diaphragm. There is some evidence that NAVA improves patient-ventilator synchrony but data on clinical outcomes are still awaited. ${ }^{14}$ Some of the limitations of NAVA include the need for an oro-/nasogastric tube for measurement of 
electrical activity of diaphragm, and limited evidence on the optimal degree of assist (NAVA level) for infants with different types and severity of respiratory conditions.

\section{Oxygen Saturation Targets and Achievement Strategies}

The ability to monitor continuously and noninvasively blood-oxygen saturation using $\mathrm{SpO}_{2}$ is one of the major breakthroughs in the medical field. Until recently, there was limited evidence on the best target $\mathrm{SpO}_{2}$ levels for preterm infants with a significant variability in $\mathrm{SpO}_{2}$ targets used by different clinicians. To answer this question, the neonatal oxygen prospective meta-analysis (NeOProM) initiative was launched which consisted of five large multicenter trials that enrolled close to 5,000 extremely preterm infants. Infants were randomized to high (91-95\%) or low (8589\%) $\mathrm{SpO}_{2}$ target ranges from birth until 36 weeks of postmenstrual age. The primary outcome of the metaanalysis, death or disability at 18 to 24 months of corrected age, was not different between the groups. However, infants assigned to the lower target $\mathrm{SpO}_{2}$ group had reduced risk of retinopathy of prematurity (ROP) requiring treatment and reduced risk of BPD. Unexpectedly, they had higher risk of death and increased risk of necrotizing enterocolitis when compared with the higher target $\mathrm{SpO}_{2}$ group. ${ }^{15}$ The results of this meta-analysis have provided some evidence base for the target $\mathrm{SpO}_{2}$ range and some uniformity in clinical management. ${ }^{16}$

Most preterm infants have oxygenation instability presenting with recurrent hypoxemia episodes requiring adjustment in oxygen supplementation by the caregivers. These episodes have been associated with significant morbidities including ROP, BPD, and worse neurologic outcomes. In the last few years, several groups have developed systems that can adjust inspired oxygen concentration automatically in an attempt to keep the $\mathrm{SpO}_{2}$ in the desired range. The use of these systems in infants on respiratory support has been shown to improve the time in target $\mathrm{SpO}_{2}$ range and to reduce the duration of hypoxemia and hyperoxemia. ${ }^{17}$ There is an urgent need for larger studies to evaluate the effect of these systems on long-term clinical outcomes.

\section{Future Directions}

Over the last half century, neonatal respiratory support has evolved significantly with increasing use of technology and ever-expanding knowledge base of respiratory physiology and factors affecting preterm lung development and injury. Some of these advances are based on good-quality evidence of improved clinical outcomes, but many have been incorporated in the clinical practice with limited evidence of benefit.

There is increasing realization that monitoring of respiratory support, both in the delivery room and later in the neonatal intensive care unit, need to be objective, continuous, and goal directed. It is possible that the use of newer technologies, such as artificial intelligence and machine learning will help integrate and analyze this wealth of information and improve clinical decision making.

As newer technologies are gradually incorporated, some of the challenges will be to define clinically relevant outcome measures for benchmarking against current strategies.

\section{Conflict of Interest}

None declared.

\section{References}

1 Fischer HS, Schmölzer GM, Cheung PY, Bührer C. Sustained inflations and avoiding mechanical ventilation to prevent death or bronchopulmonary dysplasia: a meta-analysis. Eur Respir Rev 2018;27(150):180083

2 Kirpalani H, Ratcliffe SJ, Keszler M, et al; SAIL Site Investigators. Effect of sustained inflations vs intermittent positive pressure ventilation on bronchopulmonary dysplasia or death among extremely preterm infants: the SAIL randomized clinical trial. JAMA 2019;321(12):1165-1175

3 Schmölzer GM, Morley CJ, Wong C, et al. Respiratory function monitor guidance of mask ventilation in the delivery room: a feasibility study. J Pediatr 2012;160(03):377-381

4 Welsford M, Nishiyama C, Shortt C, et al; International Liaison Committee on Resuscitation Neonatal Life Support Task Force. Initial oxygen use for preterm newborn resuscitation: a systematic review with meta-analysis. Pediatrics 2019;143(01): e20181828

5 Fischer HS, Bührer C. Avoiding endotracheal ventilation to prevent bronchopulmonary dysplasia: a meta-analysis. Pediatrics 2013;132(05):e1351-e1360

6 Doyle LW, Carse E, Adams AM, Ranganathan S, Opie G, Cheong JLY; Victorian Infant Collaborative Study Group. Ventilation in extremely preterm infants and respiratory function at 8 years. $\mathrm{N}$ Engl J Med 2017;377(04):329-337

7 Aldana-Aguirre JC, Pinto M, Featherstone RM, Kumar M. Less invasive surfactant administration versus intubation for surfactant delivery in preterm infants with respiratory distress syndrome: a systematic review and meta-analysis. Arch Dis Child Fetal Neonatal Ed 2017;102(01):F17-F23

8 Yoder BA, Albertine KH, Null DM Jr. High-frequency ventilation for non-invasive respiratory support of neonates. Semin Fetal Neonatal Med 2016;21(03):162-173

9 Roberts CT, Owen LS, Manley BJ, et al; HIPSTER Trial Investigators. Nasal high-flow therapy for primary respiratory support in preterm infants. N Engl J Med 2016;375(12):1142-1151

10 Manley BJ, Owen LS. High-flow nasal cannula: Mechanisms, evidence and recommendations. Semin Fetal Neonatal Med 2016;21 (03):139-145

11 Bancalari E, Jain D. Bronchopulmonary dysplasia: can we agree on a definition? Am J Perinatol 2018;35(06):537-540

12 Klingenberg C, Wheeler KI, McCallion N, Morley CJ, Davis PG. Volume-targeted versus pressure-limited ventilation in neonates. Cochrane Database Syst Rev 2017;10:CD003666

13 Iscan B, Duman N, Tuzun F, Kumral A, Ozkan H. Impact of volume guarantee on high-frequency oscillatory ventilation in preterm infants: a randomized crossover clinical trial. Neonatology 2015; 108(04):277-282

14 Rossor TE, Hunt KA, Shetty S, Greenough A. Neurally adjusted ventilatory assist compared to other forms of triggered ventilation for neonatal respiratory support. Cochrane Database Syst Rev 2017;10:CD012251

15 Askie LM, Darlow BA, Finer N, et al; Neonatal Oxygenation Prospective Meta-analysis (NeOProM) Collaboration. Association between oxygen saturation targeting and death or disability in extremely preterm infants in the neonatal oxygenation 
prospective meta-analysis collaboration. JAMA 2018;319(21): 2190-2201

16 Sweet DG, Carnielli V, Greisen G, et al. European consensus guidelines on the management of respiratory distress syndrome - 2016 update. Neonatology 2017;111(02):107-125

17 Poets CF, Franz AR. Automated FiO2 control: nice to have, or an essential addition to neonatal intensive care? Arch Dis Child Fetal Neonatal Ed 2017;102(01):F5-F6
18 Bottino R, Pontiggia F, Ricci C, et al. Nasal high-frequency oscillatory ventilation and $\mathrm{CO}_{2}$ removal: A randomized controlled crossover trial. Pediatr Pulmonol 2018;53(09):12451251

19 Mitra S, Singh B, El-Naggar W, McMillan DD. Automated versus manual control of inspired oxygen to target oxygen saturation in preterm infants: a systematic review and meta-analysis. J Perinatol 2018;38(04):351-360 